OPEN ACCESS

Edited by: Sissel Torre, Norwegian University of Life Sciences,

Norway

Reviewed by:

Sasan Aliniaeifard, University of Tehran, Iran

Mauricio Hunsche, University of Bonn, Germany

*Correspondence: Carl-Otto Ottosen coo@food.au.dk

Specialty section: This article was submitted to Crop and Product Physiology, a section of the journal

Frontiers in Plant Science

Received: 24 September 2020 Accepted: 23 November 2020

Published: 05 January 2021

Citation:

Palma CFF, Castro-Alves V,

Morales $L O$, Rosenqvist $E$, Ottosen CO and Strid $\AA$ (2021) Spectral Composition of Light Affects Sensitivity to UV-B and Photoinhibition in Cucumber.

Front. Plant Sci. 11:610011. doi: 10.3389/fpls.2020.610011

\section{Spectral Composition of Light Affects Sensitivity to UV-B and Photoinhibition in Cucumber}

\author{
Carolina Falcato Fialho Palma1 , Victor Castro-Alves², Luis Orlando Morales ${ }^{2}$, \\ Eva Rosenqvist ${ }^{3}$, Carl-Otto Ottosen ${ }^{1 *}$ and Åke Strid ${ }^{2}$
}

\footnotetext{
' Department of Food Science, Plant, Food \& Climate, Aarhus University, Aarhus, Denmark, ${ }^{2}$ School of Science and Technology, Örebro Life Science Centre, Örebro University, Örebro, Sweden, ${ }^{3}$ Department of Plant and Environmental Sciences, Crop Sciences, University of Copenhagen, Taastrup, Denmark
}

Ultraviolet B (UV-B) (280-315 nm) and ultraviolet A (UV-A) (315-400 nm) radiation comprise small portions of the solar radiation but regulate many aspects of plant development, physiology and metabolism. Until now, how plants respond to UV-B in the presence of different light qualities is poorly understood. This study aimed to assess the effects of a low UV-B dose $\left(0.912 \pm 0.074 \mathrm{~kJ} \mathrm{~m}^{-2}\right.$ day $^{-1}$, at a $6 \mathrm{~h}$ daily UV exposure) in combination with four light treatments (blue, green, red and broadband white at $210 \mu \mathrm{mol} \mathrm{m} \mathrm{m}^{-2} \mathrm{~s}^{-1}$ Photosynthetically active radiation [PAR]) on morphological and physiological responses of cucumber (Cucumis sativus CV. "Lausanna RZ F1"). We explored the effects of light quality backgrounds on plant morphology, leaf gas exchange, chlorophyll fluorescence, epidermal pigment accumulation, and on acclimation ability to saturating light intensity. Our results showed that supplementary UV-B significantly decreased biomass accumulation in the presence of broad band white, blue and green light, but not under red light. UV-B also reduced the photosynthetic efficiency of $\mathrm{CO}_{2}$ fixation $(\alpha)$ when combined with blue light. These plants, despite showing high accumulation of anthocyanins, were unable to cope with saturating light conditions. No significant effects of UV-B in combination with green light were observed for gas exchange and chlorophyll fluorescence parameters, but supplementary UV-B significantly increased chlorophyll and flavonol contents in the leaf epidermis. Plants grown under red light and UV-B significantly increased maximum photosynthetic rate and dark respiration compared to pure red light. Additionally, red and UV-B treated plants exposed to saturating light intensity showed higher quantum yield of photosystem II (PSII), fraction of open PSII centres and electron transport rate and showed no effect on the apparent maximum quantum efficiency of PSIl photochemistry $\left(F_{v} / F_{m}\right)$ or non-photochemical quenching, in contrast to solely red-light conditions. These findings provide new insights into how plants respond to UV-B radiation in the presence of different light spectra.

Keywords: UV-B, LEDs, light quality, chlorophyll fluorescence, gas exchange, cucumber, morphology 


\section{INTRODUCTION}

Plants perceive signals from their surrounding environment and regulate their growth and development accordingly (Smith, 1982; Huché-Thélier et al., 2016). Plants are highly sensitive to the spectral distribution of light and perceive changes in the light spectra and intensity through several protein photoreceptors (Fankhauser and Chory, 1997). These photoreceptors are sensitive to specific regions of the spectrum and overlap of action spectra of different plant photoreceptors occur, allowing the plant to detect a wider and more complex range of changes in their light environment (Heijde and Ulm, 2012). Cryptochromes and phototropins are sensitive to blue light (400-500 nm) and ultraviolet (UV) radiation A (UV-A) (315-400 nm), whereas phytochromes perceive red (600-700 nm) and far-red (700$800 \mathrm{~nm}$ ) light. Moreover, phytochromes and cryptochromes also absorb light in the green wavelength region $(500-600 \mathrm{~nm}$ ) (Folta and Maruhnich, 2007), although the response of these photoreceptors to green light is extremely weak compared to red and blue radiation, respectively.

Ultraviolet B (UV-B) radiation (290-315 nm) comprises a small but energetic portion of the solar radiation that also reaches the surface of the Earth. UV-B perceived through the photoreceptor UV RESISTANCE LOCUS 8 (UVR8) (Rizzini et al., 2011) largely affects plant morphology and metabolism (Jenkins, 2017). Plant responses to UV-B radiation are highly dependent on UV-B dosage and are also affected by whether or not the plants have previously been UV-B acclimated (HuchéThélier et al., 2016; Jenkins, 2017), as well as by the accumulation of photosynthetic pigments and phenolic compounds in the leaf epidermis. In addition, the levels of the photosynthetically active radiation (PAR) $(400-700 \mathrm{~nm})$ and the PAR/UV-B ratio are factors that strongly influence plant UV-B responses (Krizek, 2004; Lidon et al., 2012; Jenkins, 2017).

Exposure to high doses of UV-B may also induce (di)stress responses in plants, triggering the formation of free radicals [reactive oxygen species (ROS)] that cause oxidative damage (Day and Vogelmann, 1995; Jansen et al., 1998; Hideg et al., 2013). Plant responses to UV-B are highly species specific and morphological responses can be either positive (increase in plant growth) or negative (decrease in plant growth) (Huché-Thélier et al., 2016). UV-B can also reduce stem extension and leaf expansion and affect leaf thickness, leaf curling and auxiliary branching (Jansen, 2002; Wargent et al., 2009; Klem et al., 2012; Jenkins, 2017; Qian et al., 2020). Moreover, under low doses, UV$\mathrm{B}$ radiation can promote the accumulation of photoprotective compounds in the leaf tissue (Day et al., 1993). For instance, an

Abbreviations: $\alpha$, apparent quantum yield of photosynthesis; $\theta$, curvature; $A_{n}$, net photosynthetic rate; $A_{\max }$, maximum net assimilation rate; $C_{i}$, intracellular $\mathrm{CO}_{2}$ concentration; $\mathrm{CO}_{2}$, carbon dioxide; DM\%, Dry mass percentage; DM, Dry mass; E, transpiration rate; ETR, electron transport rate; FM, fresh mass; $\mathrm{F}_{\mathrm{v}} / \mathrm{F}_{\mathrm{m}}$, maximum photochemical efficiency of PSII; $\mathrm{F}_{\mathrm{q}}{ }^{\prime} / \mathrm{F}_{\mathrm{m}}{ }^{\prime}$, quantum yield or operation efficiency of PSII; $g_{s}$, stomatal conductance; ILA, individual leaf area; INL internode length; LCP, light compensation point; LMR, leaf mass ratio; NPQ, non-photochemical quenching; PAR, photosynthetically active radiation; $\mathrm{q}_{\mathrm{L}}$, fraction of open PSII centres; PSII, photosystem II; $\mathrm{R}_{\text {dark }}$, dark respiration; ROS, reactive oxygen species; SLM, specific leaf mass; TLA, total leaf area; UV-B, Ultraviolet B; $\varnothing$, stem diameter. increase in the accumulation of flavonoid glycosides in response to UV-B has been described both under artificial and natural conditions (Krizek et al., 1997; Demkura and Ballaré, 2012; Zhao et al., 2020), although in some instances UV-B had no effect or even led to decreased flavonoid accumulation (Huché-Thélier et al., 2016). Flavonoids, particularly anthocyanins, are mainly accumulated in vacuoles in the upper layer of the leaf epidermis although they can also be found in the cell wall, chloroplast envelope and cell nucleus (Hideg and Strid, 2017). Apart from having a strong free-radical scavenging activity (Lattanzio et al., 2006; Agati and Tattini, 2010), flavonoids absorb radiation in the UV range of the spectrum (280-340 nm), functioning as sunscreen compounds to protect plants from further UV induced damage (Day et al., 1993).

Contradicting results in UV-B research often derive from methodological differences among studies or from species or ecotype differences (Kalbina and Strid, 2006). Different UVB doses, light environments (natural sunlight vs. artificial lighting), other abiotic factors and species-specific responses cause variation between studies. Additionally, most UV-B research has been performed using broadband white light background under controlled conditions. Hence, there is a lack of studies depicting the effects of UV-B radiation on whole plant responses under monochromatic light backgrounds. This type of research is important to assess plant responses triggered by crosstalk between different light qualities and their impact on plant growth and development. With the development of light emitting diode (LED) technology, the use of LED lighting for horticultural production is increasing. Because of the high energy efficiency, customizable light environment and low radiant heat that allows for the placement of the lamps close to the canopy (Bourget, 2008; Darko et al., 2014; Singh et al., 2015), an interest in the use of LED lights in multilayer production has emerged. Multilayer systems allow the production of the same number of plants in a smaller area and could be relevant to use for intensive production systems such as germination of seedlings or rooting of cuttings. These production systems, although not yet economically feasible in all geographical regions when compared to normal greenhouse production (Graamans et al., 2018), rely on the sole use of LEDs and provide a unique environment for investigating new opportunities of LED lighting use, such as in monochromatic illumination and the use of UV to manipulate plant growth and development.

Blue light perception is often involved in physiological processes such as photomorphogenesis, phototropism (de Carbonnel et al., 2010), stomatal opening (Briggs and Huala, 1999; Boccalandro et al., 2012) and chlorophyll formation. Moreover, blue light induces an accumulation of several phytonutrients in the leaves, such as phenolic acids and flavonoids (Ohashi-Kaneko et al., 2007; Li and Kubota, 2009; Nascimento et al., 2013; Ouzounis et al., 2014, 2015). Red light can regulate vegetative development and plant architecture by influencing phototropism and shade-avoidance syndrome (SAS) (Fankhauser and Chory, 1997; Demotes-Mainard et al., 2016) and promote the accumulation of anthocyanins in the leaf epidermis (Mizuno et al., 2011; Zoratti et al., 2014; Garrett Owen and Lopez, 2015). Green light can inhibit stomatal opening stimulated 
by blue light (Frechilla et al., 2000; Smith et al., 2017) and promote early stem elongation (Folta, 2004). These observations suggest that different monochromatic light spectra not only have a different impact on plant growth, but could also influence plants ability to cope with abiotic stress (e.g., high light) due to a wavelength-driven accumulation of photoprotective compounds (Bayat et al., 2018).

Cucumber (Cucumis sativus L.), is an important food crop with fast growth and high sensitivity toward the spectral composition of the light environment. These aspects make cucumber an interesting crop for studying light-driven responses in plants, such as responses to UV radiation (Qian et al., 2019, 2020). The aim of this study was to investigate the effects of supplementary UV-B on growth, morphology and physiology of cucumber plants grown under different monochromatic light backgrounds. We hypothesized that: (I) different monochromatic lights have different impacts on plant morphology and (II) the response of cucumber to UV-B radiation is highly dependent on individual monochromatic light backgrounds.

\section{MATERIALS AND METHODS}

\section{Plant Material and Growing Conditions}

Cucumber seeds ( $c v$. "Lausanna RZ F1," Semenco, Asmundtorp, Sweden) were individually sown in $8 \times 8 \mathrm{~cm}$ pots filled with peat substrate (Grön Torvmull 50-liter, SW Horto, Hasselfors Garden, Örebro, Sweden). The seeds were germinated under artificial light at $200 \mu \mathrm{mol} \mathrm{m}{ }^{-2} \mathrm{~s}^{-1}$ PAR provided by metal halide lamps (MASTER HPI-T Plus 400 W/645, Phillips) during a $16 \mathrm{~h}$ photoperiod (6:00 to 22:00). The germination took place at room temperature of $22 \pm 1 / 18 \pm 1^{\circ} \mathrm{C}$ day/night and $60 \pm 5 \%$ relative humidity. Immediately after germination and opening of the cotyledons, the seedlings were randomly transferred to a room without natural light and placed in four $2 \mathrm{~m}$ high custommade trolleys with an $80 \times 170 \mathrm{~cm}$ ebb/flow watering table. Each trolley had a unique light spectral treatment (four trolleys in total) and contained 72 treatment plants. These plants were later randomly divided into 36 control plants per treatment that were only exposed to one of four different light spectra in the PAR region and 36 plants that in addition to the different light spectra were exposed to low levels of UV-B (for both treatment types, see description below). Plants remained under four different LED light treatments for 23 days at a constant light intensity of $200-215 \mu \mathrm{mol} \mathrm{m} \mathrm{m}^{-2} \mathrm{~s}^{-1}$ PAR and $16 \mathrm{~h}$ photoperiod (6:00 to 22:00). The climate conditions in the room were maintained at $22 \pm 1 / 18 \pm 1{ }^{\circ} \mathrm{C}$ day/night and $\mathrm{RH}$ of $60 \pm 5 \%$. No external supply of carbon dioxide $\left(\mathrm{CO}_{2}\right)$ was used. The cucumber plants were watered daily by flood irrigation containing commercial mineral nutrient solution (composition: $3.1 \mathrm{~g} \mathrm{NO}_{3}{ }^{-}, 2.0 \mathrm{~g} \mathrm{NH}_{4}{ }^{+}$, 1.0 g P, 4.3 g K, 0.4 g S, 0.3 g Ca, 0.4 g Mg, 35 mg Fe, 20 mg $\mathrm{Mn}, 10 \mathrm{mg} \mathrm{B}, 3.0 \mathrm{mg} \mathrm{Zn}, 1.5 \mathrm{mg} \mathrm{Cu}, 0.4 \mathrm{mg} \mathrm{Mo} ; \mathrm{pH} 6.5$ and EC $1.4 \mathrm{mS} \mathrm{cm}^{-1}$; Blomstra växtnäring, Orkla, Solna, Sweden). A portable data logger (Tinytag, Gemini Data Loggers Ltd., Chichester, United Kingdom) placed within the canopy recorded the temperature and relative humidity of each light treatment (Supplementary Figure S2).

\section{Light Treatments}

From cotyledon stage until the final harvest, plants were grown under four light treatments created in the trolleys by using FL300 LED luminaires (Senmatic, Søndersø, Denmark). The white light was created by the commercially available white broadband FL300 Sunlight (33\% blue [400-500 nm], 40\% green $[500-600 \mathrm{~nm}]$ and $27 \%$ red $[600-700 \mathrm{~nm}]$ ), while the monochromatic FL300 were custom made: blue (wavelength peak at $448 \mathrm{~nm})$, green $(528 \mathrm{~nm})$, and red $(660 \mathrm{~nm})$. The lamps were adjusted to give $200-215 \mu \mathrm{mol} \mathrm{m}^{-2} \mathrm{~s}^{-1}$ PAR at plant height (Table 1), creating a daily light integral (DLI) of approx. $10.5 \mathrm{~mol} \mathrm{~m}^{-2} \mathrm{~d}^{-1}$. Because of the comparatively low photosynthetic photon flux efficacy from green LEDs the green FL300 lamp was complemented by two custom-made narrow, green luminaires (Fluence Bioengineering, Austin, TX, United States). To eliminate stray light the sides of the trolleys were covered with non-transparent black/white plastic with the white side facing inward. Additionally, the position effect within each treatment was minimized by randomizing the treatment pots daily.

The cucumber seedlings were exposed to UV-B radiation 9 days after the start of the light treatments, when the first true leaf was fully expanded. Two open top, front and backside Perspex boxes (OTFB boxes; c.f. Qian et al., 2019) were used in each trolley to filter the UV radiation. The open top, front and backsides of the OTFB boxes were covered with sheets of Perspex to block all UV radiation for the exposure of control plants, while $0.13 \mathrm{~mm}$ cellulose diacetate (CA) sheets (Nordbergs Tekniska AB, Vallentuna, Sweden) were used for the UV-treated plants to block mainly UV-C radiation $(<292 \mathrm{~nm})$. The UV was provided by fluorescent tubes (Philips TL20/12 UV, Eindhoven, Netherlands). The spectra of both UV and the visible light were measured inside the OTFB boxes, with an OL756 double monochromator spectroradiometer (Optronic Laboratories, Orlando, FL, United States) with the orifice of the upward-directed integrating sphere placed approximately $20 \mathrm{~cm}$ above the table, at plant height (Figures 1A,B). The plant-weighted UV normalized to $300 \mathrm{~nm}$ (Thimijan et al., 1978; Yu and Björn, 1997; Kalbina et al., 2008) shows that the UV provided is biologically active in plants almost exclusively in the UV-B range (280-315 $\mathrm{nm}$ ) (Figure 1B). The plant-weighted UV normalized to $300 \mathrm{~nm}$ was quantified to $42.4 \pm 3.4 \mathrm{~mW}$ $\mathrm{m}^{-2}$, corresponding to $0.912 \pm 0.074 \mathrm{~kJ} \mathrm{~m}^{-2}$ day $^{-1}$ (at a $6 \mathrm{~h}$ daily UV exposure). Plants were exposed to UV-B

TABLE 1 | Photosynthetically active radiation of four different light backgrounds (broadband White, Blue, Green, and Red).

\begin{tabular}{lcccc}
\hline Light treatment & White & Blue & Green & Red \\
\hline PAR $[400-800 \mathrm{~nm}]$ & 214 & 212 & $201 / 180^{\#}$ & 211 \\
$\left(\mu \mathrm{mol} \mathrm{m}{ }^{-2} \mathrm{~s}^{-1}\right)$ & & & &
\end{tabular}

The values represent averages.

"Due to the extra green LEDs and the resulting architecture of the light equipment, the UV tube was hanging lower and partly shaded the green lights, thus giving lower PAR in the CA box than in the "Perspex only" box. This shading effect was not happening in the three other light qualities. 

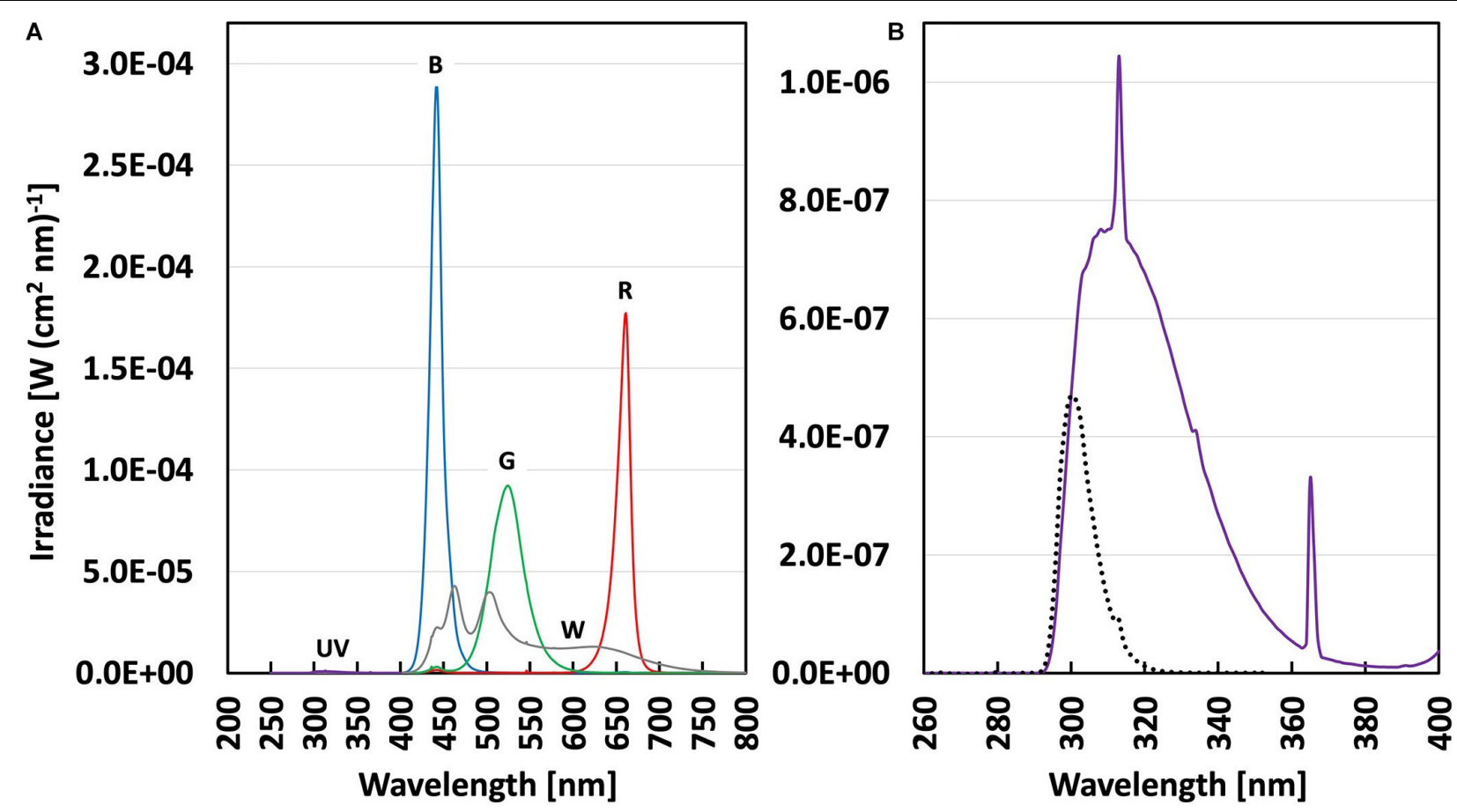

FIGURE 1 | (A) Spectral irradiance (in W( $\left(\mathrm{cm}^{2} \mathrm{~nm}\right)^{-1}$ ) in Perspex covered (control) and cellulose acetate covered (UV-B) boxes under four different PAR backgrounds (Table 1); broadband White (gray line), Blue, Green, Red (with lines of respective color) and UV-B (violet line). (B) Spectral irradiance in the UV range (violet line) with enlarged scale and the plant-weighted UV dose (black dotted line) in the UV-B treatments.

radiation for 14 days. Thereafter 22 plants per treatment were measured and harvested (see below). To investigate whether the different light acclimation regimens induced a difference in the ability to cope with photoinhibition, the remaining treatment plants were subjected to a saturating light treatment for $5 \mathrm{~h}$ at $1600 \mu \mathrm{mol} \mathrm{m} \mathrm{m}^{-2} \mathrm{~s}^{-1}$ PAR provided by two FL300 Sunlight luminaires, delivering an additional light integral of $29 \mathrm{~mol} \mathrm{~m}^{-2} 5 \mathrm{~h}^{-1}$.

\section{Plant Growth and Development}

Plant growth was assessed for 5-7 plants per treatment through destructive harvest at the end of the UV-B radiation treatment. The plant height was measured from the stem base to the apical meristem and the stem diameter $(\varnothing) 1 \mathrm{~cm}$ above the soil using a digital slide caliper (Biltema, Linköping, Sweden). The number of true leaves and leaf area (LA) was measured on scanned leaves using the Image J software (version 1.52a) (Wayne Rasband, National Institute of Health, United States). After each harvest, leaf and stem fresh mass (LFM and SFM) and dry mass (LDM and SDM) were determined after drying for 3 days at $80^{\circ} \mathrm{C}$. Specific leaf mass $(\mathrm{SLM}=$ leaf $\mathrm{DM} / \mathrm{LA})$, leaf mass ratio $(\mathrm{LMR}=$ leaf $\mathrm{DM} /$ total DM), individual leaf area (ILA = LA/leaf number), internode length (INL = height/leaf number) and dry mass per cent $(\mathrm{DM} \%=$ total DM/total FM) were calculated.

\section{Gas Exchange Measurements}

The photosynthetic $\mathrm{CO}_{2}$ assimilation rate $\left(\mathrm{A}_{\mathrm{n}}\right)$, transpiration rate $(\mathrm{E})$, stomatal conductance $\left(\mathrm{g}_{\mathrm{s}}\right)$ and intracellular $\mathrm{CO}_{2}$ concentration $\left(\mathrm{C}_{\mathrm{i}}\right)$ were estimated in seven plants per treatment by gas exchange (CIRAS-2 with PLC6(U) with a LED light source, PP Systems, Amesbury, United States) on the last fully expanded leaf on day 9 to 12 of the UV-B treatment. The conditions during measurement were $22^{\circ} \mathrm{C}$ leaf temperature, $400 \mathrm{ppm} \mathrm{CO}_{2}$ and $0.9 \pm 1.0 \mathrm{~Pa} \mathrm{kPa}^{-1}$ vapor pressure deficit (VPD). The light response curve covered 12 light levels starting at a PAR of $250 \mu \mathrm{mol} \mathrm{m}{ }^{-2} \mathrm{~s}^{-1}$, decreasing in steps to $20 \mu \mathrm{mol}$ $\mathrm{m}^{-2} \mathrm{~s}^{-1}$ and again from 250 increasing in steps to $1800 \mu \mathrm{mol}$ $\mathrm{m}^{-2} \mathrm{~s}^{-1}$. Data were logged every $5 \mathrm{~s}$ and the mean value of 1 min of steady-state was averaged for each light level. The light response curves were fitted by Solver in Excel to a nonrectangular hyperbola (Ögren, 1993) to determine plant dark respiration rate $\left(\mathrm{R}_{\mathrm{dark}}\right)$, the apparent quantum yield of $\mathrm{CO}_{2}$ assimilation based on incident light $(\alpha)$, the light compensation point (LCP), maximum net assimilation rate at light saturation $\left(A_{\max }\right)$, and the convexity $(\theta)$ of the light response curve.

\section{Chlorophyll Fluorescence Measurements}

Chlorophyll fluorescence was measured using a Mini-PAM with leaf clips (Walz, Effeltrich, Germany) on day 13 to 14 of UV$B$ radiation and after the subsequent saturating light treatment $\left(1600 \mathrm{~m}^{-2} \mathrm{~s}^{-1}\right)$ that was used to induce photoinhibition. Randomized measurements were performed in the afternoon (13:00-16:00) in 4-5 biological replicates per treatment. The $\mathrm{F}_{\mathrm{O}}$ and $F_{m}$ were measured for maximum photochemical efficiency of PSII $\left(\mathrm{F}_{\mathrm{v}} / \mathrm{F}_{\mathrm{m}}=\left(\mathrm{F}_{\mathrm{m}}-\mathrm{F}_{\mathrm{o}}\right) / \mathrm{F}_{\mathrm{m}}\right)$ after 30 min dark adaptation with aluminum foil on the last fully expanded leaf. The 
site of measurement was marked on the leaf and the plant was placed under saturating PAR $\left(1600 \pm 100 \mu \mathrm{mol} \mathrm{m} \mathrm{m}^{-2}\right.$ $\mathrm{s}^{-1}$ ) from a KL 1500 electronic halogen lamp (SCHOTT AG Lighting and Imaging, Mainz, Germany) for $30 \mathrm{~min}$ to reach steady-state photosynthesis. Thereafter, the leaf clip was placed on the marked spot, $\mathrm{F}^{\prime}$ and $\mathrm{Fm}^{\prime}$ were measured and the operation efficiency of PSII $\left(\mathrm{Fq}^{\prime} / \mathrm{Fm}^{\prime}\right)$, the electron transport rate (ETR), the fraction of open PSII centres $\left(\mathrm{q}_{\mathrm{L}}\right)$ and the non-photochemical quenching (NPQ) were calculated (Murchie and Lawson, 2013).

\section{Non-destructive Optical Absorbance Measurements}

Non-destructive measurements of chlorophyll, flavonol and anthocyanin contents were assessed on the adaxial side of the last fully developed leaf with a Dualex+ (FORCE-A, Centre Universitaire Paris Sud, Cedex, France). The four replicates per treatment were measured immediately after the daily UVB exposure.

\section{Statistical Analysis}

All data analyzed was collected from three independent experiments. Statistical analyses were performed in $\mathrm{R}$ (version 3.3.1., R Core Development Team, 2017). Linear mixed effects models were fitted using the lme function in the nlme package (Pinheiro and Bates, 2000) and with experimental replicate as a random component. The effect of the different PAR backgrounds (White, Blue, Green, Red) on plant growth, morphology and physiology was assessed using ANOVA. In case significant differences were identified among treatments, contrasts between the four PAR backgrounds were fitted using the function fit.contrasts from the gmodels package (Warnes et al., 2018). The resulting $p$-values were adjusted using the function p.adjust (Holm, 1979) (Supplementary Table S3). Additionally, the effect of supplementary UV-B irradiation was tested solely within the same PAR background and no comparison between light backgrounds was made. Differences between control and UV-B plants within the same light environment were tested using linear mixed effects models with experimental replicate as a random factor. Differences between control and UV-B-treated plants were assessed using ANOVA (Supplementary Table S4).

\section{RESULTS}

\section{Monochromatic Light Qualities Within the PAR Spectrum Differentially Regulate Growth and Development}

To investigate the spectral effect on growth and development of cucumber plants, we analyzed non-UV-B (control plants) grown under different PAR spectra 24 days after germination (Figure 2). Plants grown under blue and green light were tallest compared to plants grown under the other light spectra (Figure 2A). INL followed the same pattern with decreasing length of internodes from blue to white growth light (Figure 2B). Plants grown under red light showed lower total dry mass (TDM) compared to plants grown under the other light spectra, whilst green light plants had the highest TDM (Figure 2C). Plants grown under green light had the largest total leaf area (TLA) whilst the plants under broadband white light had the smallest (Figure 2D). The whitelight-grown plants had a higher SLM compared to plants grown under the other light spectra (Figure 2E). Plants grown under green light had the largest leaf number while blue-light plants had the smallest leaf number, compared with the other light treatments (Figure 2F).

\section{Green and Red Light Reduce Photosynthesis in Cucumber Leaves}

Light response curves were measured in the UV-control plants 9-12 days after the start of the UV-B treatment (Figure 3A). For control treatments in the absence of UV-B, plants grown under white and blue light had higher $\mathrm{A}_{\max }$ followed by the green-light grown plants, whereas the lowest $A_{\max }$ was observed in plants grown under red light (Figure 3B). The white- and blue-lightgrown plants had higher $\mathrm{R}_{\text {dark }}$ than those grown under green or red light (Figure 3C). Furthermore, plants grown under white light had the significantly highest LCP and green-light-grown plants the lowest (Figure 3D). The $\alpha$ was significantly lower in plants grown under red light compared to those grown under the other light qualities (Figure 3E). Finally, plants grown under red light had the highest $\theta$ while those grown under blue light had the lowest (Figure 3F).

\section{Monochromatic Light Qualities Induce Different Sensitivity to Saturating Light Conditions}

Chlorophyll fluorescence was measured prior to and immediately after the potentially photoinhibitory saturating light treatment ( $5 \mathrm{~h}$ at a PPFD of $1600 \mu \mathrm{mol} \mathrm{m} \mathrm{m}^{-2} \mathrm{~s}^{-1}$ ) to assess the light stress tolerance of plants grown under different light spectra. Prior to the saturating light treatment, the red-lightgrown control plants had significantly lower $\mathrm{F}_{\mathrm{v}} / \mathrm{F}_{\mathrm{m}}$ compared to plants grown under the other light spectra (Figure 4A). After the saturating light treatment, plants grown under white light had the highest $\mathrm{F}_{\mathrm{v}} / \mathrm{F}_{\mathrm{m}}$, followed by plants grown under blue, green and red monochromatic light, in descending order (Figure 4A). Prior to the saturating light treatment, the ETR and $\mathrm{q}_{\mathrm{L}}$ were significantly highest in plants grown in white or blue light, while red light-grown plants had the significantly lowest values (Figures $4 \mathrm{~B}, \mathrm{C}$ ). Finally, prior to saturating light application, plants grown under red light had significantly lower NPQ than plants grown under the other spectra, whereas after the saturating light treatment, plants grown under white light were the only ones showing significantly higher NPQ compared with plants grown under the other spectra (Figure 4D).

\section{Non-destructive Measurements of Chlorophyll and Epidermal Flavonols}

Plants grown under white light had a higher chlorophyll content compared to plants grown under blue or green light. 

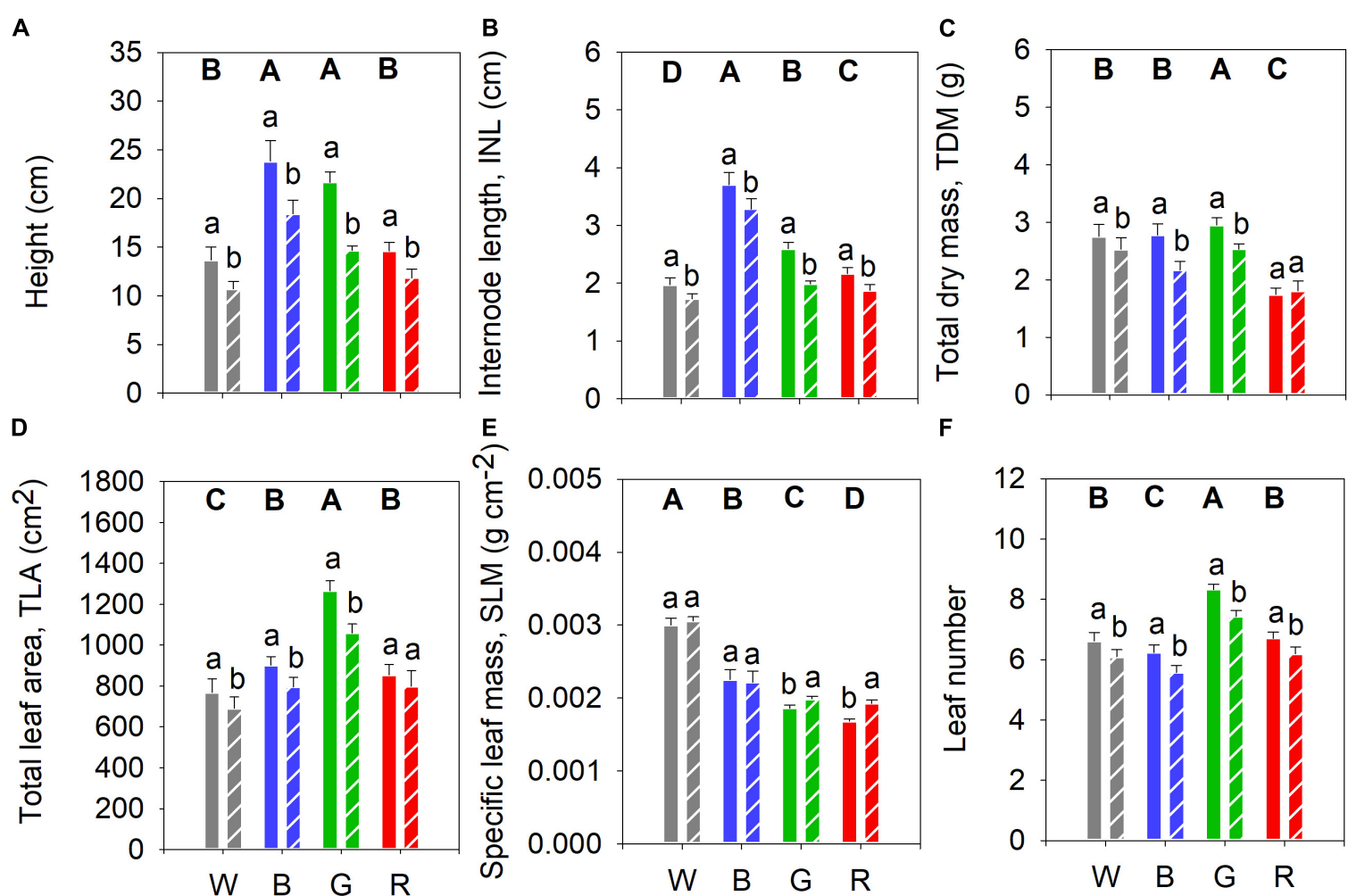

FIGURE 2 | Biomass accumulation of cucumber plants grown under four PAR backgrounds after 14 days without (solid bars) or with (dashed bars) exposure to supplementary UV-B irradiation. (A) Height (cm); (B) Internode length (INL, cm); (C) Total dry mass (TDM, g); (D) Total leaf area (TLA, cm²); (E) Specific leaf mass (SLM, $\left.\mathrm{g} \mathrm{cm}^{-2}\right)$; (F) Leaf number. Data are mean values $(n=21 \pm \mathrm{SE})$. Capital letters indicate significant differences between growth light qualities without UV-B and lower-case letters between non-UV-B-exposed plants and UV-B-exposed plants within the same light backgrounds, both at $P<0.05$.

Red light-grown plants exhibited an even lower chlorophyll content (Figure 5A). Cucumber seedlings grown under white and blue light had the highest content of epidermal flavonols, while plants grown under red and green light had the lowest concentrations (Figure 5B). Moreover, plants grown under red light showed the significantly highest anthocyanin content with leaf concentrations decreasing in the following order of light spectra: blue $>$ green $>$ white (Figure 5C).

\section{UV-B-Induced Effects on Plant Morphology Is Dependent on Monochromatic Light Background}

We also analyzed the influence of different monochromatic growth light qualities on UV-induced plant responses. Supplementary UV-B led to a decrease in plant height and INL compared to the corresponding controls (Figures 2A,B, respectively). UV-B also generally reduced plant TDM, except in plants grown under red light (Figure 2C). Moreover, after UV-B exposure, plant TLA decreased significantly in all treatments except for those grown under red light (Figure 2D). Finally, SLM increased in UV-Btreated plants grown in green and red light backgrounds (Figure 2E), whereas leaf number was decreased in all cases (Figure 2F).

\section{Supplementary UV-B Boosted Photosynthesis in Cucumber Grown Under Red Light}

The light response curves of plants grown in the control and UVB OFTB boxes were compared in order to investigate the effects of supplementary UV-B on photosynthesis parameters in cucumber plants grown under the different spectra (Figure 3A). Only UV-B-exposed plants grown under red light had a statistically significant increase in $A_{\max }$, whereas $A_{\max }$ was unaltered in all other plants (Figure 3B), which in turn resulted in a similar pattern for the $\mathrm{R}_{\text {dark }}$ and LCP parameters (Figures $3 \mathrm{C}, \mathbf{D}$, respectively). $\alpha$ significantly decreased after UV-B exposure in plants grown under white or blue light, whilst no significant differences were observed in red or green light (Figure 3E). The UV-B exposure of cucumber led to significant decreases in $\theta$ in plants grown under white or red light, whereas no significant differences were observed in plants grown under blue or green light (Figure 3F).

\section{The PAR Spectrum Changes the Effect of UV-B and the Susceptibility to} Photoinhibition

To investigate the effect of UV-B on the susceptibility to photoinhibition, plants from all treatments were exposed to $5 \mathrm{~h}$ 

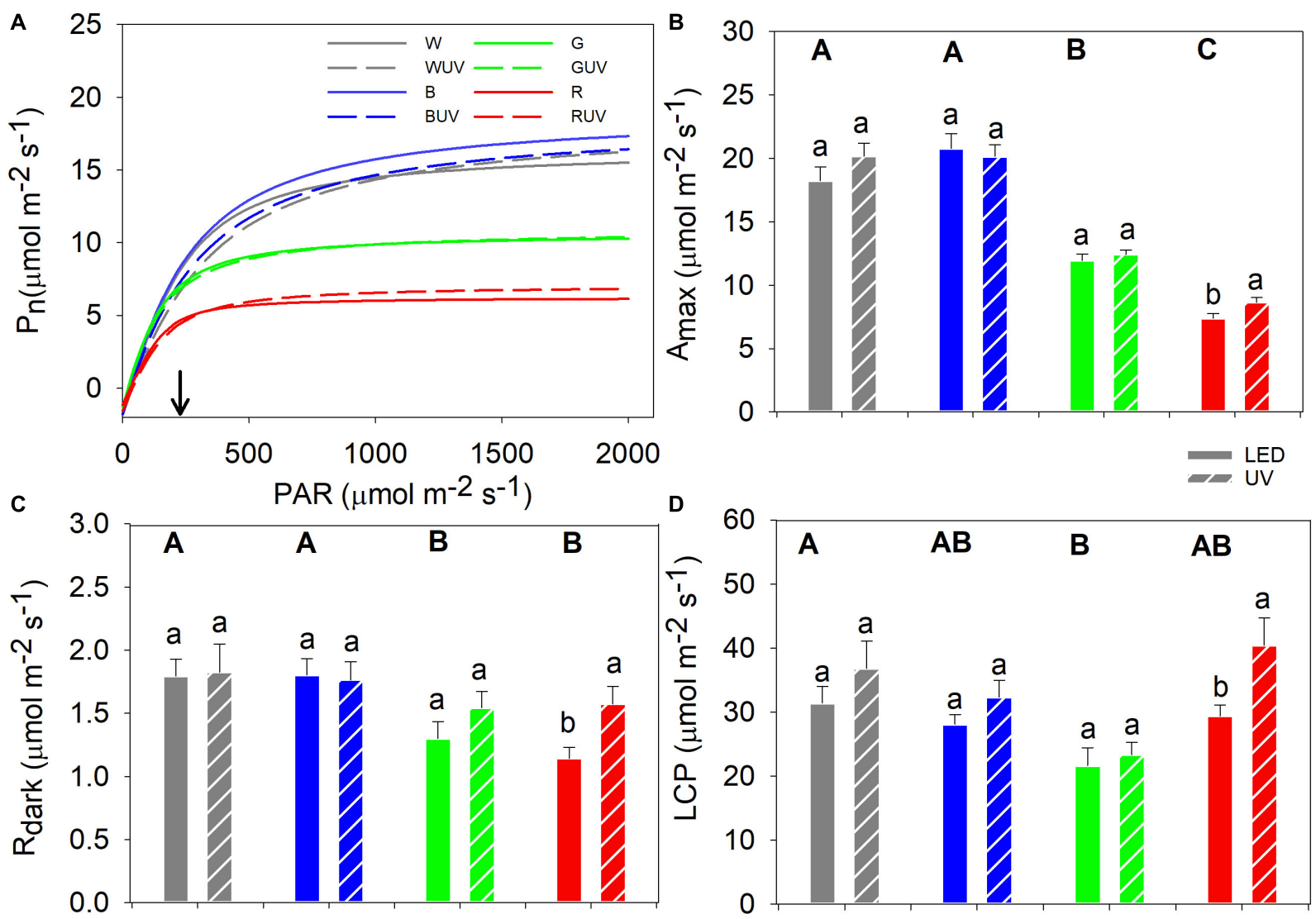

E

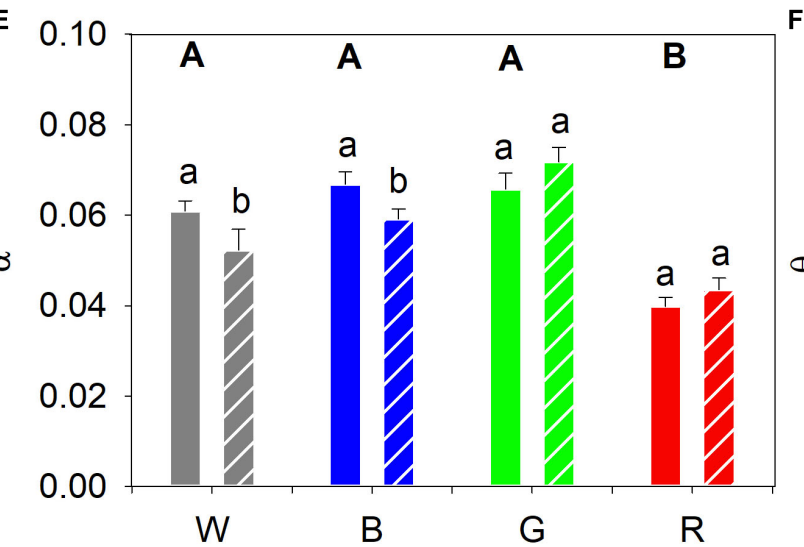

$\begin{array}{rr}\text { F } & 1.2 \\ 1.0 \\ 0.8 \\ 0 & 0.6 \\ 0.4 \\ 0.2 \\ 0.0\end{array}$

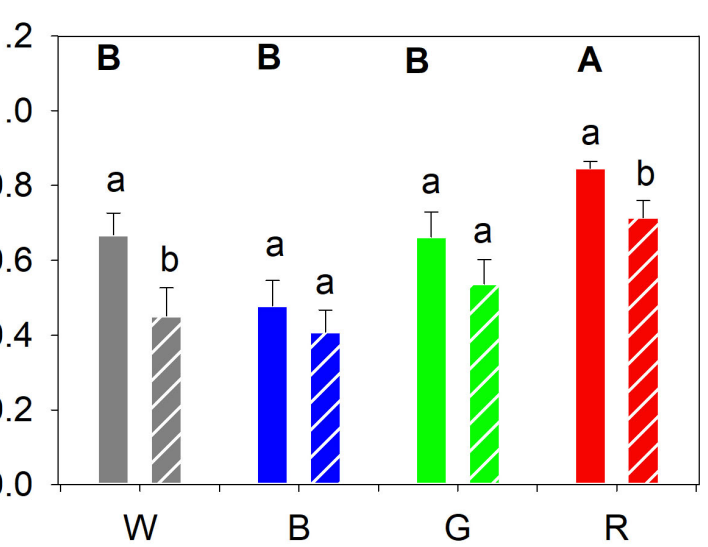

FIGURE 3 | (A) Fitted light response curves of cucumber grown under four LED light backgrounds (White, Blue, Green, and Red) without (solid bars) and with (dashed bars) exposure to supplementary UV-B radiation for 14 days [for variation of the data at light saturation refer from panels (B-F)], where the arrow indicates the growth PAR. Curve fitted parameters: (B) Maximum net assimilation rate ( $\left.A_{\max }\right)$; (C) Dark respiration (R dark); (D) Light compensation point (LCP); (E) Apparent quantum yield of photosynthesis $(\alpha)$; and $(\mathbf{F})$ convexity $(\theta)$. Bars represent the mean values $(n=21 \pm$ SE). Capital letters indicate significant differences between growth light qualities without UV-B and lower-case letters between non-UV-B-exposed plants and UV-B-exposed plants within the same PAR background, both at $P<0.05$

of saturating light after the last day of exposure to UV-B. Prior to the saturating light treatment, only plants grown under white light had a small but significant decrease in $\mathrm{F}_{\mathrm{v}} / \mathrm{F}_{\mathrm{m}}$ after UV-B exposure (Figure 4A). The $\mathrm{F}_{\mathrm{v}} / \mathrm{F}_{\mathrm{m}}$ of plants grown under the other light qualities was unaffected by UV-B. After the saturating light treatment, however, plants grown under the red PAR background showed no significant effect of UV-B on $F_{V} / F_{m}$, whilst the other
PAR backgrounds led to significant decreases in $\mathrm{F}_{\mathrm{v}} / \mathrm{F}_{\mathrm{m}}$ by UV$B$ (Figure 4A). Prior to the exposure to saturating light, ETR and $\mathrm{qL}_{\mathrm{L}}$ were reduced after UV-B irradiation in plants grown under white and blue PAR, whereas plants grown under green PAR were unaffected. UV-B exposed plants grown under red PAR were boosted (but non-significantly for ETR) (Figures 4B,C, respectively). After the saturating light treatment, plants that had 

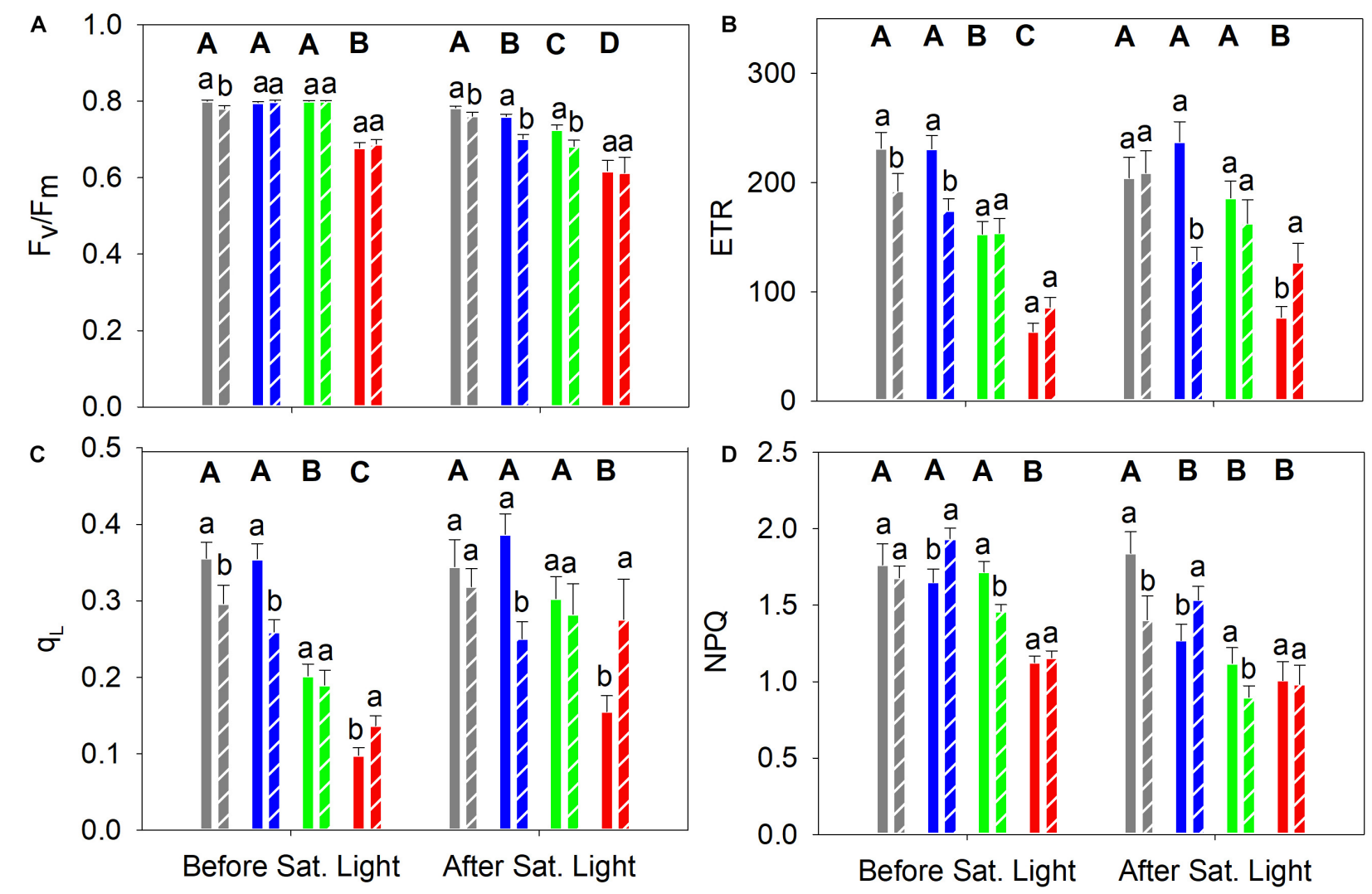

FIGURE 4 | Chlorophyll fluorescence parameters measured in cucumber plants grown under four different PAR qualities (White, Blue, Green, and Red) and without
(solid bars) or with (dashed bars) exposure to supplementary UV-B radiation for 14 days, prior to and after a $5 \mathrm{~h} \mathrm{saturating} \mathrm{light} \mathrm{treatment} \mathrm{(1600} \mu \mathrm{mol} \mathrm{m}^{-2} \mathrm{~s}^{-1}$ ). (A) Maximum photochemical efficiency $\left(F_{\mathrm{v}} / F_{m}\right)$; (B) Apparent electron transport rate (ETR); (C) Fraction of oxidized PSII (qL), (D) Non-photochemical quenching (NPQ). Bars represent mean values (Before saturating light: $n=21 \pm$ SE; After saturating light $n=15 \pm$ SE). Capital letters indicate significant differences between growth light qualities without UV-B and lower-case letters between non-UV-B-exposed plants and UV-B exposed plants within the same PAR background, both at $P<0.05$.

been exposed to UV-B showed a significant decrease in ETR when grown under blue PAR, while ETR was boosted by UV-B in plants that had red background PAR (Figure 4B). Finally, prior to the saturating light treatment, UV-B increased NPQ in plants grown under blue PAR and decreased in plants grown under green PAR (Figure 4D). After the saturating light treatment, however, UV-B decreased NPQ in white light-grown plants, while NPQ increased in plants grown under blue PAR (Figure 4D).

\section{UV-B Has a Limited Effect on Pigment Accumulation}

After the UV-B treatment, the chlorophyll content increased significantly in plants grown under white and green light compared to their controls (Figure 5A). The strong decrease in epidermal flavonol content seen in plants grown in green or red light, compared with plants grown in white or blue light, was slightly mitigated by UV-B exposure in plants grown in green light (Figure 5B). UV-B exposure of plants grown in blue light led to a significant increase in the anthocyanin content compared to the control, whereas for plants grown under the other light spectra the UV-B did not have any significant effect (Figure 5C).

\section{DISCUSSION}

\section{Monochromatic Light Differentially Affects Plant Development and Photosynthesis}

Development and physiology of cucumber plants grown under white, blue, green or red light differed substantially. Plants grown under white light were more compact, had smaller and thicker leaves compared to plants grown under the other light qualities, yet retained a high biomass accumulation. Notably, plants grown under blue light had a high biomass accumulation and had longer stems and larger leaves. It has been previously shown that blue light effects on growth were dependent on both the plant species studied and the growth conditions. While blue light inhibited stem elongation and leaf expansion, through 

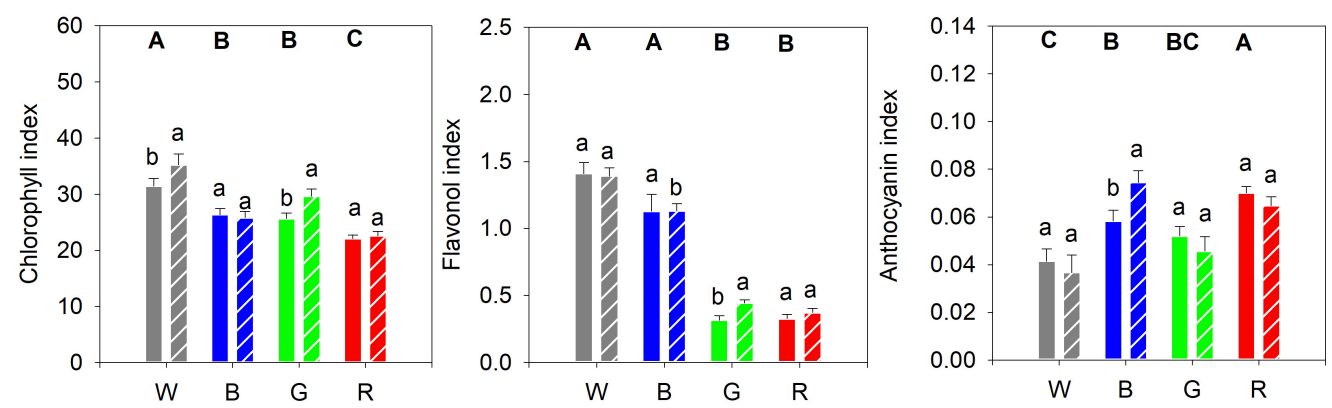

FIGURE 5 | (A) Epidermal chlorophyll, (B) flavonol and (C) anthocyanin content of cucumber plants, as measured with a DUALEX instrument, and grown under different light quality backgrounds (White, Blue, Green, and Red) and without (solid bars) or with (dashed bars) exposure to supplementary UV-B radiation for 14 days. Data are mean values ( $n=15 \pm$ SE). Capital letters indicate significant differences between growth light qualities without UV-B and lower-case letters between non-UV-B-exposed plants and UV-B exposed plants within the same PAR background, both at $P<0.05$.

a reduction in cell expansion (Cosgrove, 1981), other reports instead inferred increased stem elongation and leaf expansion under this light quality (Ahmad and Cashmore, 1997; Hernández and Kubota, 2016). This blue light induction of growth was previously associated to lack of co-action between phytochromes and cryptochromes (Ahmad and Cashmore, 1997; Hernández and Kubota, 2016) and could explain the increased INL and ILA observed in blue-light-grown plants in our study. Plants grown under either broadband white or blue light had similar photosynthetic responses, suggesting that monochromatic blue light was enough to maintain photosynthetic activity. Similar levels of NPQ, ETR, $\mathrm{F}_{\mathrm{q}}{ }^{\prime} / \mathrm{F}_{\mathrm{m}}{ }^{\prime}$ (data not shown) and $\mathrm{q}_{\mathrm{L}}$ of plants grown under blue or white light support this (Figure 4). Therefore, blue-light-grown plants are able to efficiently use photosynthates for growth.

Our data show that cucumber plants grown under green light had a higher leaf number than plants grown under any of the other light qualities, indicating an increased developmental rate in green PAR. Johkan et al. (2012) showed that small shifts in green wavelengths $(510,520$, and $530 \mathrm{~nm})$ had remarkable effects on growth and morphology in red leaf lettuce, and that under a moderate light intensity $\left(300 \mu \mathrm{mol} \mathrm{m} \mathrm{m}^{-2} \mathrm{~s}^{-1}\right)$, green light induced a higher biomass accumulation and larger leaf expansion than in plants grown under broadband white light. Green PAR is perceived by both phytochromes and cryptochromes. However, compared with the strong absorption of red and blue wavelengths, respectively, green wavelengths are poorly absorbed by both photoreceptors (Folta and Maruhnich, 2007). Green PAR penetrates deeper into leaf mesophyll than other wavelengths (Smith et al., 2017), increasing absorption of green quanta in light-depleted environments (Sun et al., 1998). The thinner and larger leaves of plants grown under green light could indicate that plants are trying to optimize light absorption by increasing both the light intercepting area and the light transmission to lower levels in the canopy since light scattering in leaves improves light penetration into the leaf especially in the green part of the spectrum (DeLucia et al., 1996). Also, absorption of green light triggered both large and fast biomass accumulation (Figure 2). In fact, green-light-grown plants had slightly larger biomass than plants grown under white or blue light, although $A_{n}$ was lower than in the white- or blue-light-grown plants (Supplementary Figure S1). Thus, plants grown under monochromatic green light managed to sustain growth and development due to improved light absorption at the canopy level as a result of a combination of larger and thinner leaves and improved light transmission. A limitation of this study was that the measurement of photosynthesis was made on the first fully developed leaf (sun leaf) from the top. It shows the acclimation of photosynthesis to the spectrum but does not give a full picture of the canopy photosynthesis. However, it could be expected that the efficient penetration of green light into leaves (DeLucia et al., 1996; Smith et al., 2017) and the distribution of the photosynthetic machinery over large and thin leaves measured under green PAR would allow efficient canopy light absorption and efficient photosynthesis also at the lower leaf levels. If comparing plants grown in white or green light by putting the values of TDM, TLA and $A_{\max }$ to 1 for white-light-grown plants, the relative values for the green-lightgrown plants will be $\mathrm{TDM}=1.07$, $\mathrm{TLA}=1.65$, and $\mathrm{A}_{\max }=0.65$. If these numbers are used to calculate a very crude estimation of the total canopy $\mathrm{A}_{\max }$, without taking internal shading and light acclimation into consideration, the white-light-grown plants will have canopy $\mathrm{A}_{\max }$ of $1 \times 1=1$, while the green-light-grown plants will have $1.65 \times 0.65=1.07$. This crude relative photosynthesis rate at light saturation on canopy level actually fits to the relative TDM for the green-light-grown plants.

In nature, a green-light-enriched environment is an indication of overgrowing vegetation triggering a shade-avoidance response resulting in stem elongation and upward leaf orientation (Zhang et al., 2011; Zhang and Folta, 2012; Wang et al., 2015). Moreover, Folta (2004) suggested that supplementary green light irradiation induces early hypocotyl elongation. Inhibition of stem elongation is a phytochrome-dependent response, and the wavelengths of our green growth light fall precisely outside the range of the phytochrome action spectrum, thus simulating a light environment lacking the red wavelengths. In our study, green light grown plants were significantly taller than the plants grown under red and broadband white light. This suggests that plants grown under green light, in addition to having thinner and larger leaves, also tried to optimize light absorption by growing taller in response to a red-depleted light environment. 
While blue growth light did not change any of the plants' photosynthetic parameters compared with plants grown in white light, plants grown under green light showed decreased $A_{\max }$, $\mathrm{R}_{\mathrm{dark}}$, and LCP, while maintaining $\alpha$ and $\theta$ at the same levels as plants grown in white or blue light (Figure 3). All these changes correspond to low-light acclimation of photosynthesis (Givnish, 1988), accompanied by lower ETR and $\mathrm{q}_{\mathrm{L}}$, and maintained NPQ, resulting in an NPQ increase in proportion to ETR. Plants grown under green light showed a large decrease in the light saturated $\mathrm{A}_{\max }$ compared with plants grown in white light. However, at the lower growth irradiance $\left(210 \mu \mathrm{mol} \mathrm{m}^{-2} \mathrm{~s}^{-1}\right)$ the decrease of $A_{n}$ was considerably smaller. Since the total biomass production was even higher in plants grown under green light than in plants grown under white PAR, this suggests that the green-light-grownplants were not source limited.

Generally, plants grown under monochromatic red PAR cannot sustain normal photosynthetic activity (Hogewoning et al., 2010; Trouwborst et al., 2010). Red-light-grown plants had a severely decreased $A_{\max }$ so that the growth was source limited with a much decreased $A_{n}$ and a lower biomass production. For plants grown under red light, $A_{\max }$ decreased more than in plants grown under green light, and when $\mathrm{R}_{\text {dark }}$ decreased, so did $\alpha$, leaving LCP unaffected. Plants grown under red PAR were the only ones showing a lower $\alpha$, which deviates from the normal pattern of acclimation to low light level (Givnish, 1988). It could be expected a lower $\alpha$ during stomatal limitation of $A_{n}$, but this was not the case since $C_{i}$ was unaffected (Supplementary Figure S1), suggesting instead a strong biochemical limitation. A decrease in $\alpha$ could also be an indication of photoinhibition (Ögren and Sjöström, 1990). Indeed, $\mathrm{F}_{\mathrm{V}} / \mathrm{F}_{\mathrm{m}}$ was significantly lower in plants grown under red PAR than in those grown under white light which agrees with previous studies showing dysfunctional photosynthesis in cucumber grown in the absence of blue PAR during growth (Hogewoning et al., 2010). NPQ is a protective mechanism through which plants dissipate excessive energy in the form of heat (Maxwell and Johnson, 2000). The low NPQ of red-lightgrown cucumber suggests a low heat dissipation, which could be associated with a strong down-regulation of the photosynthetic process. Furthermore, impairment of photosynthesis could explain the growth inhibition observed in cucumber grown under red light, manifested as plants with the smallest stem $\varnothing$ and lowest biomass accumulation (LDM, SDM, and TDM) compared with plants grown under the other light qualities. Red-lightgrown cucumber also had highest LMR, suggesting that the plants allocated as many resources as possible toward leaves to mitigate growth inhibition.

To evaluate how light acclimation affected general light stress tolerance, plants were subjected to a 5 -h photoinhibitory treatment. The applied high light stress decreased $\mathrm{F}_{\mathrm{v}} / \mathrm{F}_{\mathrm{m}}$ in all treatments. However, white-light-grown plants had the smallest decrease, suggesting a better ability to cope with saturating light conditions. Plants grown under blue, green or red light showed gradually lower $\mathrm{F}_{\mathrm{v}} / \mathrm{F}_{\mathrm{m}}$, indicating increasing sensitivity toward saturating light in that order. ETR and $\mathrm{q}_{\mathrm{L}}$ also gradually decreased in the same order, although it was only plants grown under red light that showed a statistically significant change
(Supplementary Table S3). NPQ decreased in plants grown under all different monochromatic light qualities, indicating that energy dissipation due to down-regulation of PSII increased. This was manifested as a lower $\mathrm{F}_{\mathrm{v}} / \mathrm{F}_{\mathrm{m}}$, at the expense of light-regulated heat dissipation (NPQ), particularly in red-light-grown plants.

\section{Metabolite Composition Is Affected by Spectral Composition}

We show a relation between the spectral composition and accumulation of secondary metabolites. The non-destructive measurements showed that plants grown under white light had the highest total chlorophyll content, followed by plants grown under blue, green and red light in decreasing order. This indicates the importance of blue light in the light environment for chlorophyll formation in cucumber during growth. The effects of broadband white on flavonoid content differs between plant species, but in our study, the cucumber plants grown under white PAR had the highest leaf epidermal flavonol content followed by plants grown under blue light. Plants grown under green or red light had significantly lower leaf epidermal flavonol content. In fact, Ouzounis et al. (2014) showed an increase in flavonoid content of roses, campanulas and chrysanthemums with an increasing proportion of blue light in a red background light, in contrast to a low flavonoid content in plants grown under monochromatic red light.

Anthocyanins often function as photoprotective pigments, reducing the amount of light that penetrates the leaf epidermis and preventing damage caused by excessive incident light (Day et al., 1993). In our study, red-light-grown plants had the highest anthocyanin content, followed by plants grown in blue, green and white light, respectively. This suggests that plants grown under red PAR induced anthocyanin accumulation in the leaf epidermis in order to reduce incident light and protect the photosynthetic system from further damage. An increased anthocyanin accumulation in plants grown under red light has previously been reported in red cabbage (Mizuno et al., 2011), bilberries (Zoratti et al., 2014), and lettuce (Garrett Owen and Lopez, 2015). The accumulation of anthocyanins, as well as the decreased $\mathrm{F}_{\mathrm{V}} / \mathrm{F}_{\mathrm{m}}$ and $\alpha$ suggest that the red light is a stress factor in cucumber, but that the accumulated anthocyanins were insufficient to protect the leaves from light stress by the red growth light.

\section{Monochromatic Light Treatments Modify UV-B Responses in Cucumber}

We found that a lower than ambient level of supplementary UV-B exposure led to decreased extension growth (height and INL) that mostly affected plants grown in green and red PAR, in which SLM increased. This indicates that plants developed shorter stems and thicker leaves to acclimate to UV-B (Jenkins, 2017). Moreover, a clear partitioning of biomass from stem to leaves were observed in plants grown under all light qualities after exposure to UV-B, manifested as a higher LMR. The height, leaf number and TDM were reduced and the effects were smallest in plants grown under red light. This either suggests that red-lightgrown plants are less sensitive to the low UV-B level used with 
regards to morphology, or that growth inhibition caused by red growth light itself overrides the effects of supplementary UV-B. It should also be noted that the effects of UV-B are dose dependent and high doses of UV-B radiation, much higher than those used in this study, can cause distress and reduce plant growth and development (Hideg et al., 2013). Low level supplementary UV$\mathrm{B}$ exposures reduced $\alpha$ in plants grown in white light although $\mathrm{A}_{\text {max }}$ remained unaltered. In addition, supplementary UV-B led to decreased $\mathrm{F}_{\mathrm{v}} / \mathrm{F}_{\mathrm{m}}$, ETR, and $\mathrm{q}_{\mathrm{L}}$, while no effects on NPQ were observed in white-light-grown plants, suggesting a slight downregulation of photosynthesis compared with the corresponding control plants. UV-B radiation can decrease photosynthetic capacity through a number of high dose mechanisms targeting for instance both the donor and the acceptor sides of Photosystem II or Rubisco (Jordan et al., 2016). Other such mechanisms include photodegradation of light-absorbing pigments (Prasad et al., 2004), such as chlorophyll (Strid and Porra, 1992; Nedunchezhian and Kulandaivelu, 1997) and carotenoids. However, we show that the chlorophyll content increases in cucumber grown in white light treated with UV-B compared with the corresponding control, contributing to the contradicting conclusions described in literature (Jordan et al., 2016). This may be due to different levels of UV-B used in in different studies, as well as the use of different UV-B to PAR ratios.

The use of blue light may prevent damage caused by high UV-B levels (Hoffmann et al., 2015; Escobar-Bravo et al., 2017). Hoffmann et al. (2015) demonstrated that high intensities of blue light ( $300 \mu \mathrm{mol} \mathrm{m} \mathrm{m}^{-2} \mathrm{~s}^{-1}$ ) improved the photosynthetic performance of pepper plants exposed to UV-B. The reduced UV-B damage could be explained by reduced degradation of photosynthetic pigments and by increased accumulation of epidermal UV-absorbing flavonoids synergistically induced by blue light and UV-B (Nascimento et al., 2013; Ouzounis et al., 2014; Hoffmann et al., 2015). However, this was not observed in our study using low level UV-B. Together with an unchanged $A_{\text {max }}$, decreased ETR and $\mathrm{q}_{L}$, as well as an increased NPQ in plants grown under blue PAR, we show that monochromatic blue light does not improve plant acclimation or increase photoprotection to UV-B. The production of anthocyanins has previously been shown to increase by a combination of blue PAR and UV-A in turnip seedlings (Wang et al., 2012) and apple (Arakawa et al., 1985). This agrees with our results.

Cucumbers appear less susceptible to low levels of UV-B when grown in green light, since a decrease in NPQ was the only significant UV-B-induced change in the photosynthesis parameters, suggesting a slightly increased energy flow to photochemistry. This was accompanied by higher concentrations of chlorophyll and flavonols. Most interestingly, adding UV-B to red PAR growth light boosted photosynthesis of cucumber plants compared with the corresponding red PAR control. Although a higher $\mathrm{A}_{\max }$, LCP, and $\mathrm{R}_{\text {dark }}$ indicated increased photosynthesis, this was not due to improved photochemistry (no increase in $\alpha$ ), but rather due to a positive effect on the biochemical processes regulating $\mathrm{CO}_{2}$ assimilation. Moreover, supplementary UV-B had no negative effect on $\mathrm{F}_{\mathrm{V}} / \mathrm{F}_{\mathrm{m}}$ and did not induce any additional stress to the photosynthetic machinery of red-lightgrown plants. Additionally, no changes in epidermal pigment content (chlorophyll, flavonol, and anthocyanin) were observed when supplementary UV-B was added to a red PAR growth light. The positive effects on photosynthesis may explain the lack of growth inhibition caused by UV-B in a background of red growth light.

\section{Light Spectra and UV-B Affects the Susceptibility to Photoinhibition}

The use of realistic levels of UV-B radiation play an important role in enhancing photoprotection under saturating light (Wargent et al., 2015), rather than causing further damage to the photosynthetic apparatus. After photoinhibition, plants grown under all different light qualities (but without UV-B) showed a lowered $\mathrm{F}_{\mathrm{v}} / \mathrm{F}_{\mathrm{m}}$ along a distinct gradient with the smallest effect in plants grown in white light, via blue- and green-light-grown plants, to the largest effect in plants grown in red light. In addition, supplementary UV-B lowered $F_{v} / F_{m}$ even further in plants grown in each different light quality, except for red-lightgrown plants, where $\mathrm{F}_{\mathrm{v}} / \mathrm{F}_{\mathrm{m}}$ was unaffected. This is of particular interest since ETR and $\mathrm{q}_{\mathrm{L}}$ decreased after 2 weeks of UV-B exposure prior to photoinhibitory treatment in blue-light-grown plants (unaffected $\mathrm{A}_{\max }$; Figure 3), remained the same in greenlight-grown plants (slightly reduced $\mathrm{A}_{\max }$ ), but increased in red-light-grown cucumber (strongly reduced $A_{\text {max }}$; lower $F_{v} / F_{m}$ ). We suggest that the low UV-B levels used in our study create eustress to activate defense systems, e.g., antioxidants, which put the plants in a state of "low alert" toward other stresses that may involve oxidative stress (Hideg et al., 2013), including photoinhibition. Obviously, addition of UV-B is not enough to fully overcome stress induced by red light given in the growth phase, but both $\mathrm{A}_{\max }$ and $\mathrm{q}_{\mathrm{L}}$ are significantly higher in UV-Btreated photoinhibited plants than in plants that had been grown solely in red light before photoinhibition (with a clear trend also in ETR). In fact, absolute levels of $\mathrm{q}_{\mathrm{L}}$ and ETR in UV-B-treated photoinhibited red-light-grown plants were similar as in UV-Btreated photoinhibited green- or blue-light-grown plants. If the UV-B treatment induces a low-level alert against other stresses (Jansen et al., 2019), it seems that such another stress (in this case photoinhibition) has to be of a certain magnitude for a plant to benefit from the UV-B treatment. Thus, the effect of UV$\mathrm{B}$ mitigating a second stress, such as photoinhibition, follows a gradient from no beneficial effect at all in non-stressed leaves to a beneficial effect in already light stressed leaves.

\section{CONCLUSION}

In agreement with our first hypothesis, we show that different monochromatic light backgrounds exert different responses in growth and physiology in cucumber. Monochromatic green and blue growth light, but not red, enabled normal photosynthetic functioning of leaves of cucumber plants without compromising biomass accumulation. Despite being exposed to the same light level, plants grown in green light showed low light acclimation of photosynthesis, but because of the changed canopy architecture with larger and thinner leaves these plants had the highest total biomass production. On the other hand, in plants grown in 
red light, the low light acclimation was more pronounced and accompanied by light stress symptoms that reduced $F_{\mathrm{V}} / \mathrm{F}_{\mathrm{m}}$ and also led to reduced growth.

Our data confirmed our second hypothesis that cucumber responses to UV-B are highly dependent of the spectrum of monochromatic growth light. Supplementary UV-B radiation decreased plant growth and development in plants grown under blue, green and white but not under red light. Although the results suggest dysfunctional photosynthesis in plants grown under red light, UV-B boosted some photosynthetic parameters, actually increasing the potential carbon gain. Thus, UV-B and red light could act synergistically on priming the plant antioxidant capacity and diminish negative effects of photoinhibition. However, a more in-depth study of the metabolic and molecular pathways and antioxidants triggered by the treatments is required to fully explain our findings.

The findings presented here could have a positive impact on horticultural settings. By using the right monochromatic light in early stages of cucumber production, plant development may be accelerated and thus decreasing overall production time.

\section{DATA AVAILABILITY STATEMENT}

The original contributions presented in the study are included in the article/Supplementary Material. Further inquiries can be directed to the corresponding author/s.

\section{AUTHOR CONTRIBUTIONS}

$\mathrm{CP}$ performed the experiment and most of the analysis, and prepared the manuscript. VC-A commented on the manuscript. LM assisted with analysis and worked on the manuscript. ER helped analyzing data and edited the manuscript. C-OO worked

\section{REFERENCES}

Agati, G., and Tattini, M. (2010). Multiple functional roles of flavonoids in photoprotection. New Phytol. 186, 786-793. doi: 10.1111/j.1469-8137.2010. 03269.x

Ahmad, M., and Cashmore, A. R. (1997). The blue-light receptor cryptochrome 1 shows functional dependence on phytochrome A or phytochrome B in Arabidopsis thaliana. Plant J. 11, 421-427. doi: 10.1046/j.1365-313X.1997. 11030421.x

Arakawa, O., Hori, Y., and Ogata, R. (1985). Relative effectiveness and interaction of ultraviolet-B, red and blue light in anthocyanin synthesis of apple fruit. Physiol. Plant. 64, 323-327. doi: 10.1111/j.1399-3054.1985.tb03347.x

Bayat, L., Arab, M., Aliniaeifard, S., Seif, M., Lastochkina, O., and Li, T. (2018). Effects of growth under different light spectra on the subsequent high light tolerance in rose plants. AoB Plants 10, 1-17. doi: 10.1093/aobpla/ply0 52

Boccalandro, H. E., Giordano, C. V., Ploschuk, E. L., Piccoli, P. N., Bottini, R., and Casal, J. J. (2012). Phototropins but not cryptochromes mediate the blue light-specific promotion of stomatal conductance, while both enhance photosynthesis and transpiration under full sunlight. Plant Physiol. 158, 14751484. doi: 10.1104/pp.111.187237

Bourget, C. M. (2008). An introduction to light-emitting diodes. HortScience 43, 1944-1946. doi: 10.21273/hortsci.43.7.1944 with editing of the manuscript. Ås prepared spectral figures and edited the manuscript. All authors contributed to the article and approved the submitted version.

\section{FUNDING}

The project was funded by GUDP (Danish Ministry of Food, Agriculture and Fisheries) for the project Dynamic light, Interreg North Sea project SMARTGREEN and research center iFood. This project was also funded by research grants from the Knowledge Foundation (http://kks.se; grant \#20130164), and the Swedish Research Council Formas (http://formas.se/en; grant \#942-2015-516). The project was also supported by the Faculty for Business, Science and Technology at Örebro University and by Örebro University Vice Chancellor's strategic research programme on 'Food and Health'. Furthermore, part of the Ph.D. project was covered by the Research School for Science and Technology and iFood (Aarhus University Centre for Innovative Food Research).

\section{ACKNOWLEDGMENTS}

The authors would like to thank Dr. Irina Kalbina for the technical assistance and guidance. We also thank Nikolaj Bjerring Jensen and Dr. Rong Zhou for the helpful discussion and critical evaluation of the manuscript.

\section{SUPPLEMENTARY MATERIAL}

The Supplementary Material for this article can be found online at: https://www.frontiersin.org/articles/10.3389/fpls.2020. 610011/full\#supplementary-material

Briggs, W. R., and Huala, E. (1999). Blue-light photoreceptors in higher plants. Annu. Rev. Cell Dev. Biol. 15, 33-62. doi: 10.1146/annurev.cellbio.15.1.33

Cosgrove, D. J. (1981). Rapid suppression of growth by blue light. Plant Physiol. 67, 584-590. doi: 10.1104/pp.68.6.1447

Darko, E., Heydarizadeh, P., Schoefs, B., and Sabzalian, M. R. (2014). Photosynthesis under artificial light: the shift in primary and secondary metabolism. Philos. Trans. R. Soc. London Ser. B Biol. Sci. 369:20130243. doi: 10.1098/rstb.2013.0243

Day, T. A., Martin, G., and Vogelmann, T. C. (1993). Penetration of UV-B radiation in foliage: evidence that the epidermis behaves as a non-uniform filter. Plant. Cell Environ. 16, 735-741. doi: 10.1111/j.1365-3040.1993.tb0 0493.x

Day, T. A., and Vogelmann, T. C. (1995). Alterations in photosynthesis and pigment distributions in pea leaves following UV-B exposure. Physiol. Plant. 94, 433-440. doi: 10.1111/j.1399-3054.1995.tb00950.x

de Carbonnel, M., Davis, P., Roelfsema, M. R. G., Inoue, S.-I., Schepens, I., Lariguet, P., et al. (2010). The Arabidopsis PHYTOCHROME KINASE SUBSTRATE2 protein is a phototropin signaling element that regulates leaf flattening and leaf positioning. Plant Physiol. 152, 1391-1405. doi: 10.1104/pp.109.15 0441

DeLucia, E. H., Nelson, K., Vogelmann, T. C., and Smith, W. K. (1996). Contribution of intercellular reflectance to photosynthesis in shade leaves. Plant Cell Environ. 19, 159-170. doi: 10.1111/j.1365-3040.1996.tb00237.x 
Demkura, P. V., and Ballaré, C. L. (2012). UVR8 mediates UV-B-induced Arabidopsis defense responses against Botrytis cinerea by controlling sinapate accumulation. Mol. Plant 5, 642-652. doi: 10.1093/mp/sss025

Demotes-Mainard, S., Péron, T., Corot, A., Bertheloot, J., Le Gourrierec, J., Pelleschi-Travier, S., et al. (2016). Plant responses to red and far-red lights, applications in horticulture. Environ. Exp. Bot. 121, 4-21. doi: 10.1016/j. envexpbot.2015.05.010

Escobar-Bravo, R., Klinkhamer, P. G. L., and Leiss, K. A. (2017). Interactive effects of UV-B light with abiotic factors on plant growth and chemistry, and their consequences for defense against arthropod herbivores. Front. Plant Sci. 8:278. doi: $10.3389 /$ fpls.2017.00278

Fankhauser, C., and Chory, J. (1997). Light control of plant development. Annu. Rev. Cell Dev. Biol. 13, 203-229. doi: 10.1146/annurev.cellbio.13.1.203

Folta, K. M. (2004). Green light stimulates early stem elongation. Plant Physiol. 135, 1407-1416. doi: 10.1104/pp.104.038893.1

Folta, K. M., and Maruhnich, S. A. (2007). Green light: a signal to slow down or stop. J. Exp. Bot. 58, 3099-3111. doi: 10.1093/jxb/erm130

Frechilla, S., Talbott, L. D., Bogomolni, R. A., and Zeiger, E. (2000). Reversal of blue light-stimulated stomatal opening by green light. Plant Cell Physiol. 41, 171-176. doi: $10.1093 / \mathrm{pcp} / 41.2 .171$

Garrett Owen, W., and Lopez, R. G. (2015). End-of-production supplemental lighting with red and blue light-emitting diodes (LEDs) influences red pigmentation of four lettuce varieties. HortScience 50, 676-684. doi: 10.21273/ hortsci.50.5.676

Givnish, T. J. (1988). Adaptation to sun and shade: a whole-plant perspective. Aust. J. Plant Physiol. 15, 63-92. doi: 10.1071/pp9880063

Graamans, L., Baeza, E., van den Dobbelsteen, A., Tsafaras, I., and Stanghellini, C. (2018). Plant factories versus greenhouses: comparison of resource use efficiency. Agric. Syst. 160, 31-43. doi: 10.1016/j.agsy.2017.11.003

Heijde, M., and Ulm, R. (2012). UV-B photoreceptor-mediated signalling in plants. Trends Plant Sci. 17, 230-237. doi: 10.1016/j.tplants.2012.01.007

Hernández, R., and Kubota, C. (2016). Physiological responses of cucumber seedlings under different blue and red photon flux ratios using LEDs. Environ. Exp. Bot. 121, 66-74. doi: 10.1016/j.envexpbot.2015.04.001

Hideg, É, Jansen, M. A. K., and Strid, ̊̊ (2013). UV-B exposure, ROS, and stress: inseparable companions or loosely linked associates? Trends Plant Sci. 18, 107-115. doi: 10.1016/j.tplants.2012.09.003

Hideg, É, and Strid, A. (2017). "The effects of UV-B on the biochemistry and metabolism of plants," in UV-B Radiation and Plant Life. Molecular Biology and Ecology, ed. B. R. Jordan (Wallingford: CAB International), 90-110. doi: $10.1079 / 9781780648590.0090$

Hoffmann, A. M., Noga, G., and Hunsche, M. (2015). High blue light improves acclimation and photosynthetic recovery of pepper plants exposed to UV stress. Environ. Exp. Bot. 109, 254-263. doi: 10.1016/j.envexpbot.2014.06.017

Hogewoning, S. W., Trouwborst, G., Maljaars, H., Poorter, H., van Ieperen, W., and Harbinson, J. (2010). Blue light dose-responses of leaf photosynthesis, morphology, and chemical composition of Cucumis sativus grown under different combinations of red and blue light. J. Exp. Bot. 61, 3107-3117. doi: $10.1093 / \mathrm{jxb} / \mathrm{erq} 132$

Holm, S. (1979). A simple sequentially rejective multiple test procedure. Scand. J. Stat. 6, 65-70.

Huché-Thélier, L., Crespel, L., Gourrierec, J. L., Morel, P., Sakr, S., and Leduc, N. (2016). Light signaling and plant responses to blue and UV radiations perspectives for applications in horticulture. Environ. Exp. Bot. 121, 22-38. doi: 10.1016/j.envexpbot.2015.06.009

Jansen, M. A. K. (2002). Ultraviolet-B radiation effects on plants: induction of morphogenic responses. Physiol. Plant. 116, 423-429. doi: 10.1034/j.1399-3054. 2002.1160319.x

Jansen, M. A. K., Bilger, W., Hideg, É, Strid, Å, Aphalo, P., Brelsford, C., et al. (2019). Editorial: interactive effects of UV-B radiation in a complex environment. Plant Physiol. Biochem. 134, 1-8. doi: 10.1016/j.plaphy.2018. 10.021

Jansen, M. A. K., Gaba, V., and Greenberg, B. M. (1998). Higher plants and UVB radiation: balancing damage, repair and acclimation. Trends Plant Sci. 3, 131-135. doi: 10.1016/S1360-1385(98)01215-1

Jenkins, G. I. (2017). Photomorphogenic responses to ultraviolet-B light. Plant Cell Environ. 40, 2544-2557. doi: 10.1111/pce.12934
Johkan, M., Shoji, K., Goto, F., Hahida, S., and Yoshihara, T. (2012). Effect of green light wavelength and intensity on photomorphogenesis and photosynthesis in Lactuca sativa. Environ. Exp. Bot. 75, 128-133. doi: 10.1016/j.envexpbot.2011. 08.010

Jordan, B. R., Strid, A., and Wargent, J. J. (2016). "What role does UVB play in determining photosynthesis?," in Handbook of Photosynthesis (Boca Raton: CRC Press), 275-286. doi: 10.1201/9781315372136-16

Kalbina, I., Li, S., Kalbin, G., Björn, L. O., and Strid, Å (2008). Two separate UV-B radiation wavelength regions control expression of different molecular markers in Arabidopsis thaliana. Funct. Plant Biol. 35, 222-227. doi: 10.1071/FP07197

Kalbina, I., and Strid, $\AA$ (2006). Supplementary ultraviolet-B irradiation reveals differences in stress responses between Arabidopsis thaliana ecotypes. Plant Cell Environ. 29, 754-763. doi: 10.1111/j.1365-3040.2005.01436.x

Klem, K., Ač, A., Holub, P., Kováč, D., Špunda, V., Robson, T. M., et al. (2012). Interactive effects of PAR and UV radiation on the physiology, morphology and leaf optical properties of two barley varieties. Environ. Exp. Bot. 75, 52-64. doi: 10.1016/j.envexpbot.2011.08.008

Krizek, D. T. (2004). Influence of PAR and UV-A in determining plant sensitivity and photomorphogenic responses to UV-B radiation. Photochem. Photobiol. 79:307. doi: 10.1562/2004-01-27-ir.1

Krizek, D. T., Mirecki, R. M., and Britz, S. J. (1997). Inhibitory effects of ambient levels of solar UV-A and UV-B radiation on growth of cucumber. Physiol. Plant. 100, 886-893. doi: 10.1111/j.1399-3054.1997.tb00014.x

Lattanzio, V., Lattanzio, V. M. T., Cardinali, A., and Amendola, V. (2006). Role of phenolics in the resistance mechanisms of plants against fungal pathogens and insects. Phytochemistry 37, 23-67.

Li, Q., and Kubota, C. (2009). Effects of supplemental light quality on growth and phytochemicals of baby leaf lettuce. Environ. Exp. Bot. 67, 59-64. doi: 10.1016/j.envexpbot.2009.06.011

Lidon, F. J. C., Reboredo, F. H., Leitão, A. E., Silva, M. M. A., Duarte, M. P., and Ramalho, J. C. (2012). Impact of UV-B radiation on photosynthesis - an overview. Emirates J. Food Agric. 24, 546-556. doi: 10.9755/ejfa.v24i6.14673

Maxwell, K., and Johnson, G. N. (2000). Chlorophyll fluorescence-a practical guide. J. Exp. Bot. 51, 659-668. doi: 10.1093/jexbot/51.345.659

Mizuno, T., Amaki, W., and Watanabe, H. (2011). Effects of monochromatic light irradiation by LED on the growth and anthocyanin contents in leaves of cabbage seedlings. Acta Hortic. 907, 179-184. doi: 10.17660/ActaHortic.2011.907.25

Murchie, E. H., and Lawson, T. (2013). Chlorophyll fluorescence analysis: a guide to good practice and understanding some new applications. J. Exp. Bot. 64 , 3983-3998. doi: 10.1093/jxb/ert208

Nascimento, L. B. S., Leal-Costa, M. V., Coutinho, M. A. S., Moreira, N. D. S., Lage, C. L. S., Barbi, N. D. S., et al. (2013). Increased antioxidant activity and changes in phenolic profile of Kalanchoe pinnata (Lamarck) persoon (Crassulaceae) specimens grown under supplemental blue light. Photochem. Photobiol. 89, 391-399. doi: 10.1111/php.12006

Nedunchezhian, N., and Kulandaivelu, G. (1997). Changes induced by ultraviolet-B $(280-320 \mathrm{~nm})$ radiation to vegetative growth and photosynthetic characteristics in field grown Vigna unguiculata L. Plant Sci. 123, 85-92. doi: 10.1016/S01689452(97)04583-4

Ögren, E. (1993). Convexity of the photosynthetic light-response curve in relation to intensity and direction of light during growth. Plant Physiol. 101, 1013-1019. doi: 10.1104/pp.101.3.1013

Ögren, E., and Sjöström, M. (1990). Estimation of the effect of photoinhibition on the carbon gain in leaves of a willow canopy. Planta 181, 560-567. doi: 10.1007/BF00193011

Ohashi-Kaneko, K., Takase, M., Kon, N., Fujiwara, K., and Kurata, K. (2007). Effect of light quality on growth and vegetable quality in leaf lettuce, spinach and komatsuna. Environ. Control Biol. 45, 189-198. doi: 10.2525/ecb.45.189

Ouzounis, T., Fretté, X., Rosenqvist, E., and Ottosen, C. O. (2014). Spectral effects of supplementary lighting on the secondary metabolites in roses, chrysanthemums, and campanulas. J. Plant Physiol. 171, 1491-1499. doi: 10. 1016/j.jplph.2014.06.012

Ouzounis, T., Razi Parjikolaei, B., Fretté, X., Rosenqvist, E., and Ottosen, C.O. (2015). Predawn and high intensity application of supplemental blue light decreases the quantum yield of PSII and enhances the amount of phenolic acids, flavonoids, and pigments in Lactuca sativa. Front. Plant Sci. 6:19. doi: $10.3389 /$ fpls.2015.00019 
Pinheiro, J., and Bates, D. M. (2000). "Linear mixed-effects models: basic concepts and examples," in Mixed-Effects Models in S and S-PLUS, eds J. C. Pinheiro, J. Pinheiro, and D. Bates (New York, NY: Springer), 3-56. doi: 10.1007/0-38722747-4_1

Prasad, S. M., Dwivedi, R., Zeeshan, M., and Singh, R. (2004). UV$\mathrm{B}$ and cadmium induced changes in pigments, photosynthetic electron transport activity, antioxidant levels and antioxidative enzyme activities of Riccia sp. Acta Physiol. Plant. 26, 423-430. doi: 10.1007/s11738-0040033-8

Qian, M., Kalbina, I., Rosenqvist, E., Jansen, M. A. K., Teng, Y., and Strid, $\AA$ (2019). UV regulates the expression of phenylpropanoid biosynthesis genes in cucumber (Cucumis sativus L.) in an organ and spectrum dependent manner. Photochem. Photobiol. Sci. 18, 424-433. doi: 10.1039/C8PP00 $480 \mathrm{C}$

Qian, M., Rosenqvist, E., Flygare, A. M., Kalbina, I., Teng, Y., Jansen, M. A. K., et al. (2020). UV-A light induces a robust and dwarfed phenotype in cucumber plants (Cucumis sativus L.) without affecting fruit yield. Sci. Hortic. 263:109110. doi: 10.1016/j.scienta.2019.109110

Rizzini, L., Favory, J. J., Cloix, C., Faggionato, D., O’Hara, A., Kaiserli, E., et al. (2011). Perception of UV-B by the Arabidopsis UVR8 protein. Science 332, 103-106. doi: 10.1126/science. 1200660

Singh, D., Basu, C., Meinhardt-Wollweber, M., and Roth, B. (2015). LEDs for energy efficient greenhouse lighting. Renew. Sustain. Energy Rev. 49, 139-147. doi: 10.1016/j.rser.2015.04.117

Smith, H. (1982). Light quality, photoperception, and plant strategy. Annu. Rev. Plant Physiol. 33, 481-518. doi: 10.1146/annurev.pp.33.060182.002405

Smith, H., McAusland, L., and Murchie, E. H. (2017). Don't ignore the green light: exploring diverse roles in plant processes. J. Exp. Bot. 68, 2099-2110. doi: $10.1093 /$ jxb/erx098

Strid, A, and Porra, R. J. (1992). Alterations in pigment content in leaves of Pisum sativum after exposure to supplementary UV-B. Plant Cell Physiol. 33, 1015-1023. doi: 10.1093/oxfordjournals.pcp.a078325

Sun, J., Nishio, J. N., and Vogelmann, T. C. (1998). Green light drives CO2 fixation deep within leaves. Plant Cell Physiol. 39, 1020-1026. doi: 10.1093/ oxfordjournals.pcp.a029298

Thimijan, R. W., Carns, H. R., and Campbell, L. E. (1978). Final Report (EPAIAG-D6-0168): Radiation Sources and Relative Environmental Control for Biological and Climatic Effects of UV Research (BACER). Washington D.C.: USDA-ETA.

Trouwborst, G., Oosterkamp, J., Hogewoning, S. W., Harbinson, J., and van Ieperen, W. (2010). The responses of light interception, photosynthesis and fruit yield of cucumber to LED-lighting within the canopy. Physiol. Plant. 138, 289-300. doi: 10.1111/j.1399-3054.2009.01333.x
Wang, Y., Zhang, T., and Folta, K. M. (2015). Green light augments far-red-lightinduced shade response. Plant Growth Regul. 77, 147-155. doi: 10.1007/s10725015-0046-X

Wang, Y., Zhou, B., Sun, M., Li, Y., and Kawabata, S. (2012). UV-A light induces anthocyanin biosynthesis in a manner distinct from synergistic blue + UV-B light and UV-A/blue light responses in different parts of the hypocotyls in turnip seedlings. Plant Cell Physiol. 53, 1470-1480. doi: 10.1093/pcp/pcs088

Wargent, J. J., Moore, J. P., Roland Ennos, A., and Paul, N. D. (2009). Ultraviolet radiation as a limiting factor in leaf expansion and development. Photochem. Photobiol. 85, 279-286. doi: 10.1111/j.1751-1097.2008.00433.x

Wargent, J. J., Nelson, B. C. W., Mcghie, T. K., and Barnes, P. W. (2015). Acclimation to UV-B radiation and visible light in Lactuca sativa involves upregulation of photosynthetic performance and orchestration of metabolomewide responses. Plant Cell Environ. 38, 929-940. doi: 10.1111/pce.12392

Warnes, A. G. R., Bolker, B., Lumley, T., and Randall, C. (2018). Package 'gmodels. Vienna: R Foundation for Statistical Computing.

Yu, S. G., and Björn, L. O. (1997). Effects of UVB radiation on light-dependent and light-independent protein phosphorylation in thylakoid proteins. J. Photochem. Photobiol. B Biol. 37, 212-218. doi: 10.1016/S1011-1344(96)07409-X

Zhang, T., and Folta, K. M. (2012). Green light signaling and adaptive response. Plant Signal. Behav. 7, 75-78. doi: 10.4161/psb.7.1.18635

Zhang, T., Maruhnich, S. A., and Folta, K. M. (2011). Green light induces shade avoidance symptoms. Plant Physiol. 157, 1528-1536. doi: 10.1104/pp.111. 180661

Zhao, B., Wang, L., Pang, S., Jia, Z., Wang, L., Li, W., et al. (2020). UV-B promotes flavonoid synthesis in Ginkgo biloba leaves. Ind. Crops Prod. 151:112483. doi: 10.1016/j.indcrop.2020.112483

Zoratti, L., Sarala, M., Carvalho, E., Karppinen, K., Martens, S., Giongo, L., et al. (2014). Monochromatic light increases anthocyanin content during fruit development in bilberry. BMC Plant Biol. 14:377. doi: 10.1186/s12870-0140377-1

Conflict of Interest: The authors declare that the research was conducted in the absence of any commercial or financial relationships that could be construed as a potential conflict of interest.

Copyright (c) 2021 Palma, Castro-Alves, Morales, Rosenqvist, Ottosen and Strid. This is an open-access article distributed under the terms of the Creative Commons Attribution License (CC BY). The use, distribution or reproduction in other forums is permitted, provided the original author(s) and the copyright owner(s) are credited and that the original publication in this journal is cited, in accordance with accepted academic practice. No use, distribution or reproduction is permitted which does not comply with these terms. 